\title{
L-carnitine ameliorates peripheral neuropathy in diabetic mice with a corresponding increase in insulin-like growth factor-1 level
}

\author{
RUI WANG ${ }^{1 *}$, LIUXIN WANG $^{1 *}$, CAISHUN ZHANG ${ }^{1}$, YAN ZHANG $^{2}$, \\ YUAN LIU ${ }^{1}$, LIMIN SONG ${ }^{1}$, RUIXIA MA ${ }^{3}$ and JING DONG ${ }^{4}$
}

\author{
Departments of ${ }^{1}$ Special Medicine and ${ }^{2}$ Nephrology, Medical College, Qingdao University, Qingdao, Shandong 266071; \\ ${ }^{3}$ Department of Nephrology, Affiliated Hospital of Qingdao University, Qingdao, Shandong 266003; \\ ${ }^{4}$ Department of Physiology, Medical College, Qingdao University, Qingdao, Shandong 266071, P.R. China
}

Received March 4, 2018; Accepted October 22, 2018

DOI: $10.3892 / \mathrm{mmr} .2018 .9647$

\begin{abstract}
Diabetic peripheral neuropathy (DPN) is one of the common complications in diabetes, affecting more than half of patients with diabetes. L-carnitine (LC) was recently demonstrated to serve a positive role in ameliorating DPN. Therefore, the aim of the present study was to investigate the underlying mechanisms of LC in ameliorating DPN. Male Kunming mice were randomly assigned into five groups, including the control group, diabetes mellitus group, pre-treatment group, treatment group and post-treatment group. Type 2 diabetes was induced in mice using a combination of high-fat diet and streptozotocin injection. Subsequently, peripheral neuropathy was measured and the levels of LC, insulin and insulin-like growth factor-1 (IGF-1) were detected. When diabetic mice were treated with $\mathrm{LC}$, the levels of IGF-1 in the plasma and pancreas were increased. In addition, hyperalgesia, as determined by the tail-flick test as well as food intake, body weight and blood glucose levels were decreased. An amelioration of demyelination, axonal atrophy and mitochondria swelling in the nerve fibres of diabetic mice was also observed. The present study demonstrated that LC
\end{abstract}

Correspondence to: Professor Jing Dong, Department of Physiology, Medical College, Qingdao University, 308 Ningxia Road, Qingdao, Shandong 266071, P.R. China

E-mail: dongjing6@hotmail.com

Dr Ruixia Ma, Department of Nephrology, Affiliated Hospital of Qingdao University, 16 Jiangsu Road, Qingdao, Shandong 266003, P.R. China

E-mail: anita1685@163.com

${ }^{*}$ Contributed equally

Abbreviations: DPN, Diabetic peripheral neuropathy; LC, L-carnitine; IGF-1, insulin-like growth factor-1; T2DM, type 2 diabetes mellitus; HFD, high-fat diet; STZ, streptozotocin; DDW, double distilled water

Key words: type 2 diabetes mellitus, L-carnitine, diabetic peripheral neuropathy, insulin-like growth factor-1 ameliorated peripheral neuropathy in type 2 diabetic mice and the effect of LC may in part be mediated by an increase in local and circulatory IGF-1 levels.

\section{Introduction}

Diabetic peripheral neuropathy (DPN) is a frequent complication of diabetes that influences the nervous system (1) and $>50 \%$ of patients with diabetes are affected. The major manifestations of DPN are paresthesia, hyperalgesia, sensory loss and foot ulceration, which are associated with considerable morbidity, mortality and impaired quality of life in patients (2). Surgery or symptomatic treatments are currently the only options for treating DPN $(3,4)$. Drugs that are currently used for DPN treatment have demonstrated variable efficacy and the use of them are limited due to adverse effects $(5,6)$. These limitations have led to more extensive research into finding effective alternative options for treating DPN.

L-carnitine ( $\beta$-hydroxy- $\gamma$ - $\mathrm{N}$-trimethylaminobutyric acid; LC), the biologically active form of carnitine, is an amino acid-like agent involved in the transit of long chain fatty acids that is synthesized in various tissues (7) and serves an important role in fatty acid oxidation (8). Bach et al (9) reported that the skeletal muscle, heart, intestines, testis and in particular liver, can hydroxylate $\gamma$-butyrobetaine into carnitine. LC was demonstrated to have a role in ameliorating diabetic neuropathy by decreasing insulin resistance and increasing cellular uptake of glucose $(10,11)$. Stevens et al (12) also demonstrated that diabetic patients with complications, including hyperlipidemia and neuropathy exhibited lower concentrations of LC compared with patients who did not harbour these complications. Additional studies have revealed the preventive and therapeutic effects of LC on peripheral nerve function and structural abnormalities (13-16) as well as on endothelial blood flow (17).

Insulin-like growth factor-1 (IGF-1) is an insulin-like hormone that participates in maintaining glucose homeostasis. It is structurally homologous to insulin and shares similar in vitro metabolic activity (18). Numerous prospective epidemiological studies have revealed that alterations in serum levels of IGF-1 are associated with the development of type 2 diabetes mellitus (T2DM) (19-23). IGF-1 binding proteins 
(IGFBPs) are hypothesized to have a role in glucose metabolism, with IGFBP-1 acutely regulating glucose levels through its effects on free IGF-I (24).

Additionally, studies have indicated that LC supplementation in the plasma is associated with the levels of IGF-1 (25) and LC may contribute to the activation of IGF-1 (26). However, the role of LC in ameliorating diabetic neuropathy has not been clarified. In the present study, the effect of exogenous LC on DPN in streptozotocin (STZ)-induced diabetic mice was investigated and possible mechanisms of action were examined.

\section{Materials and methods}

Animals. A total of 40 male Kunming specific-pathogen-free mice (weight, 15-17 g; age, 3 weeks), were obtained from the Institute of Drug Control (Qingdao, China). The mice had free access to food and water, and were housed in a temperature-controlled $\left(24 \pm 1^{\circ} \mathrm{C}\right.$; humidity $\left.50-60 \%\right)$ animal room (illumination from 7:00 to 19:00). All mice were fed a high-fat diet (HFD; 59\% standard mouse food, 18\% lard, 20\% sugar and $3 \%$ egg yolk). Only 27 of the 40 mice survived due to the low survival rate of diabetic mice. The study was approved by the Ethics Committee of Medical Department of Qingdao University (Qingdao, China). The protocols used for handling the mice were provided by the Qingdao University Center for Human Functional Experiments of the Medical College Animal Care Committee (Qingdao, China), which meets the guidelines set by the National Institutes of Health Guide for Care and Use of Laboratory Animals.

LC treatment. LC was obtained from the Northeast Pharmaceutical Group Co., Ltd. (Shenyang, China) and was prepared in double distilled water (DDW). To study the preventive effect of LC on peripheral neuropathy in type 2 diabetic mice, the mice were randomly divided into five groups ( $\mathrm{n}=8 /$ group): Control, diabetes, pre-treatment, treatment and post-treatment (27). For the pre-treatment group, intragastric administration of $125 \mathrm{mg} / \mathrm{kg}$ LC was performed once a day until the mice were 12 weeks old. For the treatment group, mice were administered $125 \mathrm{mg} / \mathrm{kg} \mathrm{LC} 24 \mathrm{~h}$ following diabetes induction ( 9 weeks $+24 \mathrm{~h}$ ) until the mice were 12 weeks old. For the post-treatment group, mice were randomly divided into two equal groups and administered either LC $(125 \mathrm{mg} / \mathrm{kg})$ or DDW when mice were raised 13 weeks until they were 16 weeks old. A summary of the experimental design is presented in Table I.

STZ treatment. STZ was obtained from Sigma-Aldrich (Merck KGaA, Darmstadt, Germany) and was prepared in $0.1 \mathrm{M}$ citrate buffer (pH 4.5). A total of two low doses of $100 \mathrm{mg} / \mathrm{kg}$ STZ were delivered to mice in the diabetic, pre-treatment, treatment and post-treatment group by intraperitoneal injection at the age of 6 and 9 weeks. Age-matched mice in the control group were injected with DDW. Mice with insulin levels within the average range of the control group and fasting blood glucose levels $>12 \mathrm{mmol} / \mathrm{l}$ were considered to be type 2 diabetic mice (28).

Body weight, food intake and blood glucose measurements. Body weight and daily food intake were monitored using an electric balance [PL1501-S; Mettler-Toledo International Trading (Shanghai) Co., Ltd., Shanghai, China] once a week. Blood samples were collected from the tail vein at the age of 3 weeks, 6 weeks ( $24 \mathrm{~h}$ following the first STZ injection), 9 weeks ( $24 \mathrm{~h}$ following the second STZ injection) and 12 weeks. Blood glucose was determined using a glucometer (B. Braun, Melsungen AG, Hesse, Germany) for all the samples.

Preparation of plasma, sciatic nerve and pancreas samples. All mice were sacrificed at the age of 12 weeks except for mice in the post-treatment group, which were sacrificed at 16 weeks of age. Blood samples $(1 \mathrm{ml})$ were drawn from the retro-orbital sinus, followed by centrifugation at $4^{\circ} \mathrm{C}$ for $15 \mathrm{~min}$ at $3,000 \mathrm{xg}$ and were then stored at $-20^{\circ} \mathrm{C}$. A total of two segments of sciatic nerve were removed from the two lateral sides. One segment of sciatic nerve was used for ultra-structural observation under an electron microscope. The sciatic nerve was immediately immersed at room temperature for $1 \mathrm{~h}$, then at $4^{\circ} \mathrm{C}$ for $>3 \mathrm{~h}$ in Sotelo fixing solution, composed of $1 \%$ paraformaldehyde and $2.5 \%$ glutaraldehyde in cacodylate buffer $0.1 \mathrm{~mol} / 1$, adjusted at $\mathrm{pH}$ 7.35. Then they were post-fixed by immersion in $1 \%$ osmium tetroxide for $30 \mathrm{~min}$ at room temperature and dehydrated in graded alcohol solutions and propylene oxide. Following embedding in Epon 812, microsections of 1-2 $\mu \mathrm{m}$ were cut and stained at room temperature for 15-30 min on the copper grid with $4 \%$ uranyl acetate and then with Reynold's lead citrate for 5-10 min. Pancreas tissues were homogenized in $0.01 \mathrm{M}$ PBS and the supernatants obtained by centrifugation at $4{ }^{\circ} \mathrm{C}$ for $15 \mathrm{~min}$ at $12,000 \mathrm{xg}$ were stored at $-20^{\circ} \mathrm{C}$.

Determination of plasma and pancreas LC levels using high-performance liquid chromatography (HPLC). Concentrations of LC in the plasma and pancreas were detected by HPLC using an excitation and emission wavelengths of 248 and $418 \mathrm{~nm}$, respectively. This method was first established in the authors' lab (29). HPLC was performed using a 474 fluorescence detector (Waters 2690 Separations Module; Waters Corporation, Milford, MA, USA). A reversed-phase Hypersil BDS-C18 column (200x4.6 mm, $5 \mathrm{~mm}$ particle size, Thermo Fisher Scientific, Inc., Waltham, MA, USA) equipped with a precolumn Hypersil BDSC18 (10x4 mm, 5 mm particle size) was used. The mobile phase was composed of methanol[ammoniun formate $20 \mathrm{mM}$, formic acid $0.5 \%$, triethylamine $0.2 \%(\mathrm{pH} \mathrm{3})] 67: 33 \mathrm{v} / \mathrm{v}$, and its flow rate was $1 \mathrm{ml} / \mathrm{min}$. The samples were refrigerated in an auto sampler for storage, which was a part of the Waters 2690 Alliance system. The complete procedure was run for $60 \mathrm{~min}$. The injection volumes for test samples and standards varied between 50 and $100 \mu \mathrm{l}$ depending on the sample concentration. The column was equilibrated with a minimum of 5 injections $(50 \mu \mathrm{l})$ of sample diluent buffer until a stable baseline was obtained. Experiments were performed at ambient temperature.

Measurement of plasma insulin levels. The plasma insulin levels were detected by ELISA using a mouse insulin ELISA kit (Catalog \# EMINS; Invitrogen; Thermo Fisher Scientific, Inc.), according to the manufacturer's protocol. Absorbance at $450 \mathrm{~nm}$ was measured using a microplate reader (M5; MD-SpectraMax; Molecular Devices, LLC., San Jose, CA, USA). 
Table I. Experimental design.

Treatment

\begin{tabular}{|c|c|c|c|c|}
\hline Groups & 3 weeks & 6 weeks & 9 weeks & 12 weeks \\
\hline Control & HFD+DDW & HFD+DDW (CB) & HFD+DDW (CB) & - \\
\hline DM & HFD+DDW & HFD+DDW (STZ) & HFD+DDW (STZ) & - \\
\hline Pre-treatment & $\mathrm{HFD}+\mathrm{LC}$ & HFD+LC (STZ) & HFD+LC (STZ) & - \\
\hline Treatment & HFD+DDW & HFD+DDW (STZ) & HFD+LC (STZ) & - \\
\hline Post-treatment & HFD+DDW & HFD+DDW (STZ) & HFD+DDW (STZ) & HFD+LC/DDW \\
\hline
\end{tabular}

Control, $n=6$; DM, n=5; Pre-treat, $n=3$; Treat, n=5, Post-treat, $n=8$. All administrations of LC were given intragastrically. At the age of 6 and 9 weeks, mice were injected twice with STZ or CB, respectively. CB, citrate buffer; DDW, double distilled water; DM, diabetes mellitus; HFD, high-fat diet; LC, L-carnitine; STZ, streptozotocin.

Tail-flick test. The tail-flick latency test was used to measure the reaction latency of the peripheral nerve to thermal stimulus. The tails of mice were immersed in $49^{\circ} \mathrm{C}$ water and when a withdrawal response occurred, the response latency was recorded. The cut-off time for maximum latency was $10 \mathrm{sec}$ to avoid tail tissue damage. The tests were carried out once a week starting at 9 weeks of age (following the second STZ injection).

Peripheral neuropathy measurement. A sample of the sciatic nerve was processed according to standard procedures for the preparation of samples for electron microscope visualization (30). The ultrastructure of the sciatic nerve was observed by JEOL 1200 EX transmission electron microscope (JEOL USA, Inc., Peabody, MA, USA) and ultra-structural morphometric analysis was performed on electron micrographs of nerves using ImageJ (v1.8.0; National Institutes of Health, Bethesda, MD, USA). The area of the axon (A) and myelin sheath (MS) of sciatic nerves was used to calculate the ratio of axon to myelin sheath area (A/MS).

Measurement of IGF-1 concentration in sciatic nerves and plasma. The concentration of IGF-1 in the sciatic nerve and plasma was determined using a mouse IGF-1 Quantikine ELISA kit (cat. no. MG100; R\&D; Bio-Techne, Minneapolis, MN, USA). The total protein was quantified using the bicinchoninic acid Protein Assay kit (cat. no. 80815-500; Tiandz, Inc., Beijing, China). Tissue IGF-1 content is expressed as IGF-1 $\mu \mathrm{g} / \mathrm{g}$ total protein.

Statistical analysis. Data are presented as the mean \pm standard error of the mean of 2 repeated experiments. Statistical differences between dependent variables were examined with one-way analysis of variance followed by Student-Newman-Keuls post hoc test. All data were analyzed using SPSS version 20.0 (IBM Corp., Armonk, NY, USA). P $<0.05$ was considered to indicate a statistically significant difference.

\section{Results}

Concentration of L-carnitine in the plasma and pancreas. De Palo et al (31) previously reported that diabetes mellitus causes a significant decrease in LC levels. To investigate the effect of LC in diabetic mice, intragastric administration of LC was performed. The results demonstrated that there were significantly decreased levels of LC in the plasma and pancreas of diabetic mice compared with the control $(\mathrm{P}<0.01)$. LC levels were significantly elevated in the plasma $(\mathrm{P}<0.01$; Fig. $1 \mathrm{~A})$ and pancreas $(\mathrm{P}<0.01$; Fig. 1B) of mice treated with LC compared with diabetic mice. In addition, the plasma LC levels of mice in the treatment group were increased compared with in the control group.

Changes in blood glucose levels, plasma insulin levels, body weight and food intake. Following intragastric administration of LC, blood glucose levels, plasma insulin levels, body weight and food intake were monitored. Blood glucose levels of mice treated with LC were significantly increased compared the control group $(\mathrm{P}<0.01)$, but significantly decreased compared with the diabetes group $(\mathrm{P}<0.05$; Table II). The blood glucose levels of mice in the pre-treatment group, where mice where treated with LC prior to the appearance of diabetes, were lower compared with mice in the treatment group, where mice were treated with LC following the appearance of diabetes. Higher plasma insulin levels were observed in mice treated with LC compared with in diabetic mice. Overall, LC appeared to have beneficial effects on diabetes. When mice were aged 12 weeks, the average body weight of mice treated with LC prior to the appearance of diabetes was lower compared with other mice. From week 9 onwards, there was a significant difference in body weight between the pre-treatment and control group ( $\mathrm{P}<0.05$; Fig. 2). The food intake of diabetic mice was increased compared with the mice in the control group, which was consistent with clinical characteristics of T2DM (32). The food intake of mice treated with LC was significantly decreased compared with mice in the control group and the diabetes group $(\mathrm{P}<0.05$; Table II). These results indicated that LC ameliorated certain symptoms of diabetes.

Effect of LC on the tail-flick latency test. To determine the effect of LC on hyperalgesia in diabetes, the tail-flick latency test was performed. Non-diabetic control mice had a stable 
Table II. Blood glucose, plasma insulin levels and food intake in diabetic mice with or without L-carnitine treatment.

\begin{tabular}{lrrrr}
\hline Group & \multicolumn{1}{c}{ Control } & \multicolumn{1}{c}{ DM } & Pre-treatment & Treatment \\
\hline Blood glucose (mmol/l) & $6.23 \pm 0.36$ & $19.81 \pm 2.03^{\mathrm{c}}$ & $10.65 \pm 0.92^{\mathrm{a}, \mathrm{c}}$ & $13.61 \pm 1.93^{\mathrm{c}}$ \\
Insulin (mIU/l) & $12.55 \pm 0.42$ & $12.02 \pm 0.64$ & $17.50 \pm 2.69^{\mathrm{a}}$ & $21.80 \pm 2.56^{\mathrm{a}}$ \\
Food intake (g/day) & $9.00 \pm 0.80$ & $9.40 \pm 0.40$ & $5.40 \pm 0.50^{\mathrm{a}}$ & $7.80 \pm 0.23^{\mathrm{a}, \mathrm{b}}$ \\
\hline
\end{tabular}

All values are expressed as the mean \pm standard error of the mean. The data was analyzed using repeated measures method one-way analysis of variant. ${ }^{\mathrm{a}} \mathrm{P}<0.05$ vs. the diabetic group; ${ }^{\mathrm{b}} \mathrm{P}<0.05$ vs. the pre-treatment group; ${ }^{\mathrm{c}} \mathrm{P}<0.05$ vs. the control group. DM, diabetes mellitus.

A

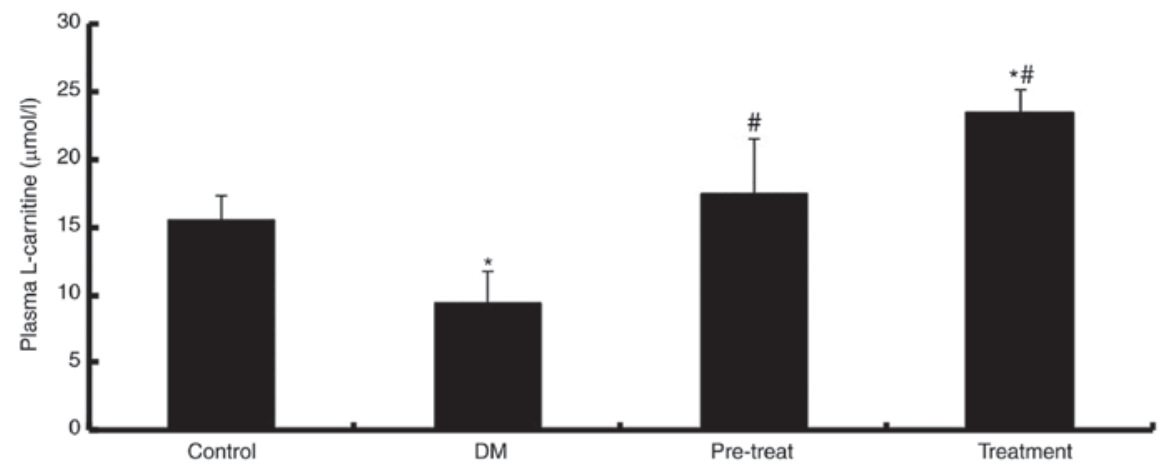

B

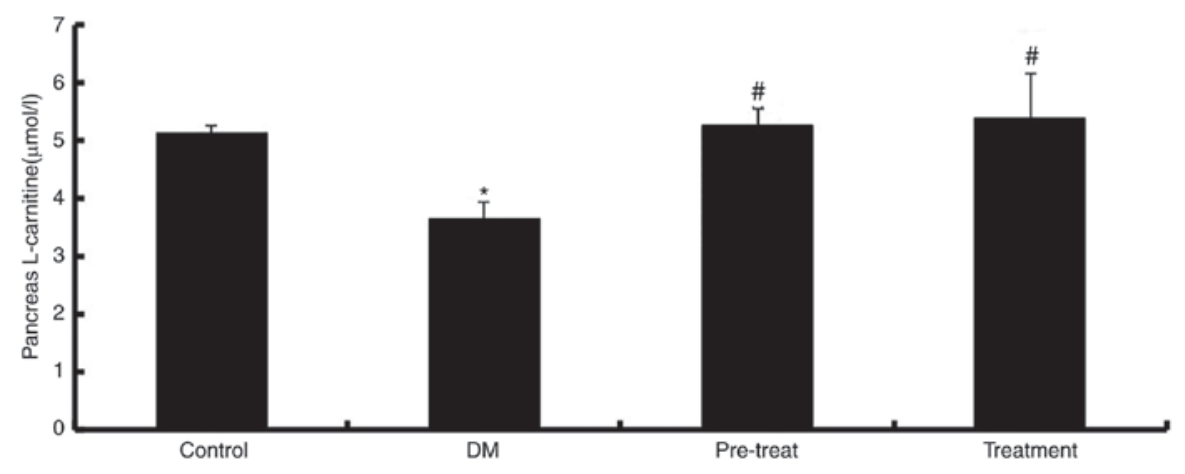

Figure 1. L-carnitine levels in the (A) plasma and (B) pancreas of type 2 diabetic mice with or without L-carnitine treatment, as determined by high-performance liquid chromatography. Control, $\mathrm{n}=6$; DM, $\mathrm{n}=5$; Pre-treat, $\mathrm{n}=3$; Treatment, $\mathrm{n}=5$. "P $<0.05$ vs. Control; $\mathrm{P}<0.05$ vs. DM. DM, diabetes mellitus; Pre-treat, pre-treatment.

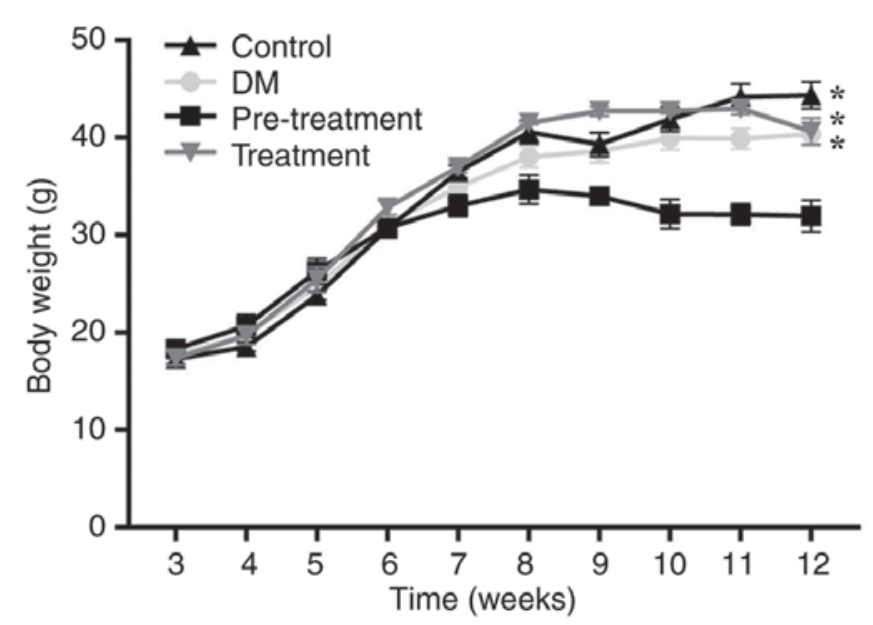

Figure 2. Effect of L-carnitine treatment on body weight in type 2 diabetic mice. Control, $n=6$; DM, $n=5$; Pre-treatment, $n=3$, Treatment, $n=5$. A11 values are expressed as the mean \pm standard error of the mean. ${ }^{*} \mathrm{P}<0.05$ vs. Pre-treatment. DM, diabetes mellitus. tail-flick latency of $\sim 4.9 \pm 0.2 \mathrm{sec}$ throughout the entire procedure. However, diabetic mice exhibited enhanced thermal hyperalgesia from the age of 12-13 weeks (3-4 weeks following diabetes induction). The tail-flick latencies in diabetic mice were significantly shortened to $1.9 \mathrm{sec}$ at 13 weeks of age $(\mathrm{P}<0.01$; Fig. 3A). In the pre-treatment group, neither hyperalgesia nor hypoalgesia were observed in tail-flick latencies test compared with the control group (Fig. 3A). The treatment group also demonstrated significantly improved tail-flick latencies compared with diabetic mice $(\mathrm{P}<0.05)$.

Furthermore, the effects of LC on tail-flick responses in mice with advanced stage diabetes were investigated. In the post-treatment group, the latency of tail-flick responses were significantly decreased to the shortest time $(\sim 1.9 \mathrm{sec})$ at 13 weeks old and then gradually increased to the same value as the control mice at 16 weeks old (Fig. 3B), which demonstrated that LC ameliorated hyperalgesia. At 17 weeks old, there were no significant differences between the control and post-treatment group (P>0.05; Fig. 3B). 

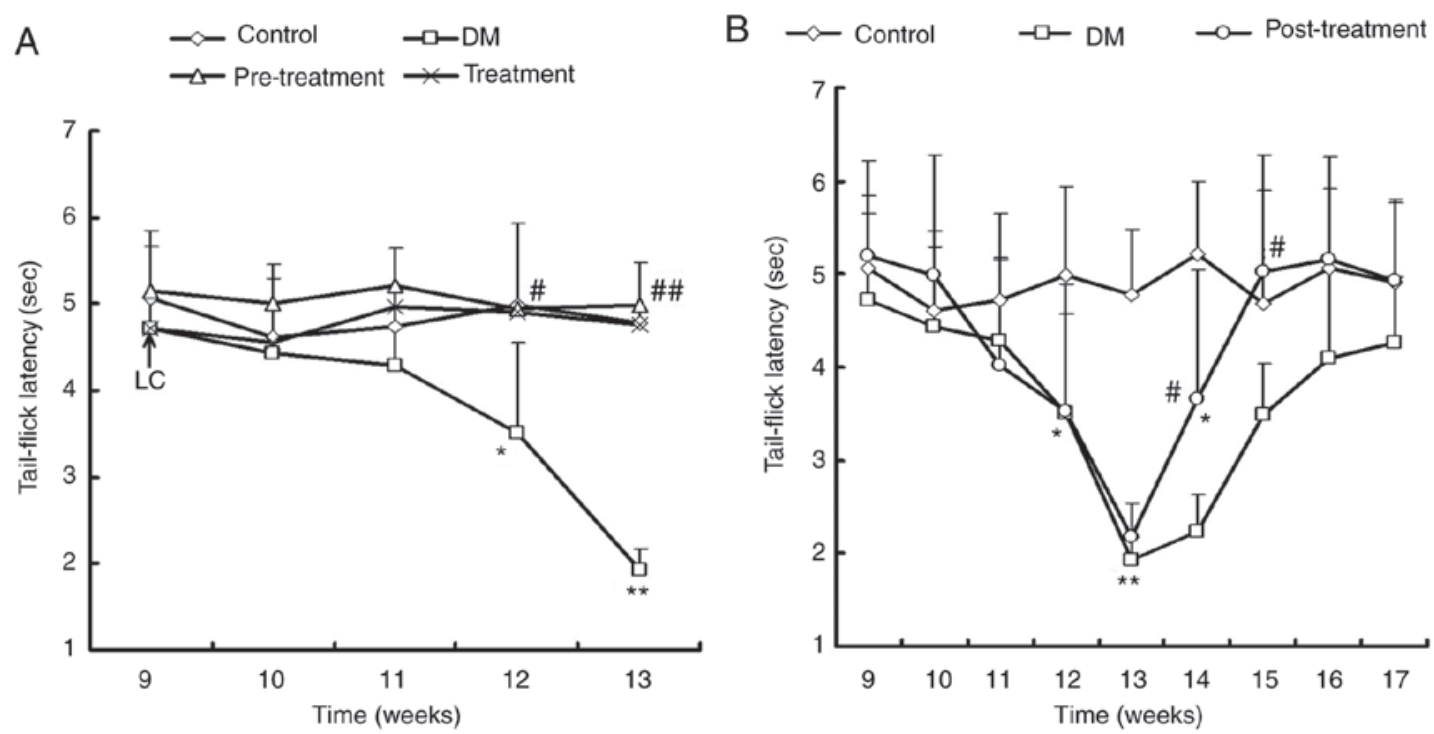

Figure 3. Change in tail-flick latency. Effect of L-carnitine treatment on tail-flick latency in mice with (A) early or (B) advanced stage diabetes. Control, $\mathrm{n}=6$; DM, $n=5$; Pre-treatment, $n=3$; Treatment, $n=5$; Post-treatment, $n=6 .{ }^{*} \mathrm{P}<0.05$ and ${ }^{* *} \mathrm{P}<0.01$ vs. the control; ${ }^{*} \mathrm{P}<0.05$ and ${ }^{\# \#} \mathrm{P}<0.01$ vs. DM. DM, diabetes mellitus.

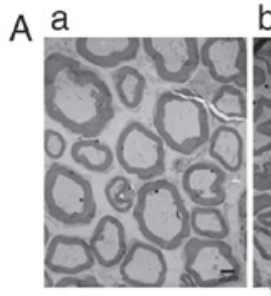

b

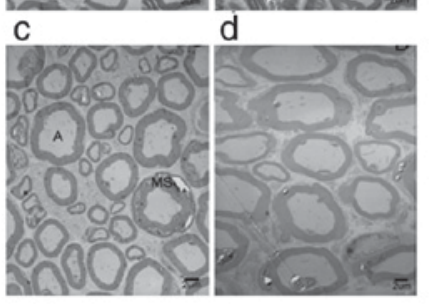

$\mathrm{B}^{\mathrm{a}}$
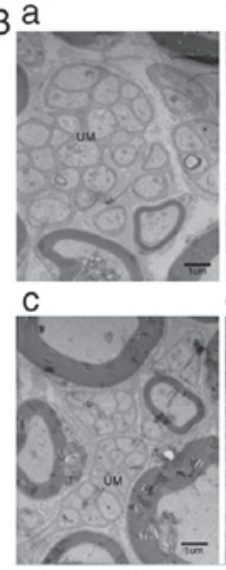

b

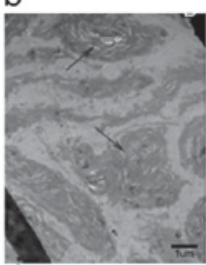

d

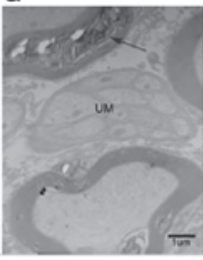

$\mathrm{Ca}$
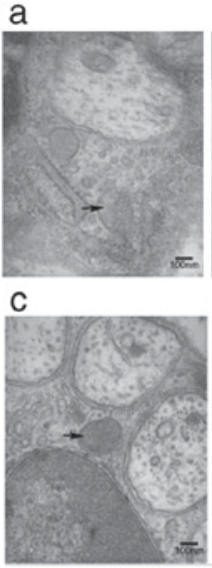

b

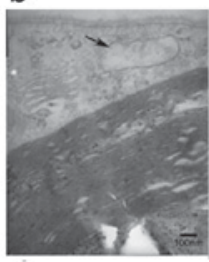

d

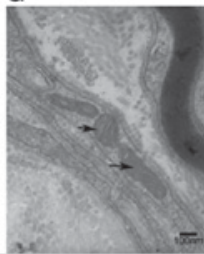

D

\begin{tabular}{cccc}
\hline & Axon area $\left(\mathrm{nm}^{2}\right)$ & Myelin area $\left(\mathrm{nm}^{2}\right)$ & Ratio \\
\hline Control & 22019.55 & 29856.8 & 0.7375 \\
DM & 15789.5 & 31981.8 & 0.493703 \\
Pre-treatment & 11841.26 & 16695.68 & 0.709241 \\
Treatment & 26237.39 & 34296.72 & 0.765012 \\
\hline
\end{tabular}

Figure 4. Ultrastructural morphologic analysis of sciatic nerves isolated from type 2 diabetic mice with or without L-carnitine treatment, using transmission electron microscopy. (A) Scale bar, $2 \mu \mathrm{m}$. (B) Scale bar, $1 \mu \mathrm{m}$. (C) Scale bar, $100 \mathrm{~nm}$. (a) Control group, (b) DM group, (c) pre-treatment group and (d) treatment group. The arrows indicate delamination of myelin lamellae, atrophy and deletion of axon, and deformed nerve fibers. (D) The ratio of axon to myelin sheath area was determined. A, axon; DM, diabetes mellitus; MS, myelin sheath; UM, ultrastructural morphologic.

Effect of LC on peripheral neuropathy. Hur et al (33) reported that nerve conduction velocity was decreased in patients with T2DM. Ding et al (34) demonstrated that sciatic nerves exhibited signs of damage in diabetic control rats, including swelling and dilatation of mitochondria and endoplasmic reticulum in Schwann cells as well as deranged myelin sheaths with lighter electron density. To investigate the influence of LC on peripheral neuropathy, examination of the ultrastructure and morphology of the sciatic nerve was performed. As presented in Fig. 4, most myelinated nerve fibers in the control group mice exhibited complete and regular structures and clear mitochondrial cristae. The nerves of diabetic mice revealed delamination of myelin lamellae, atrophy and deletion of axons as well as deformed nerve fibers, with swelling and rupture of mitochondria in Schwann cells. Following administration of LC, these effects were ameliorated. The morphometry of nerves in the pre-treatment group was similar compared to that observed for the control group. The A/MS reflects the 

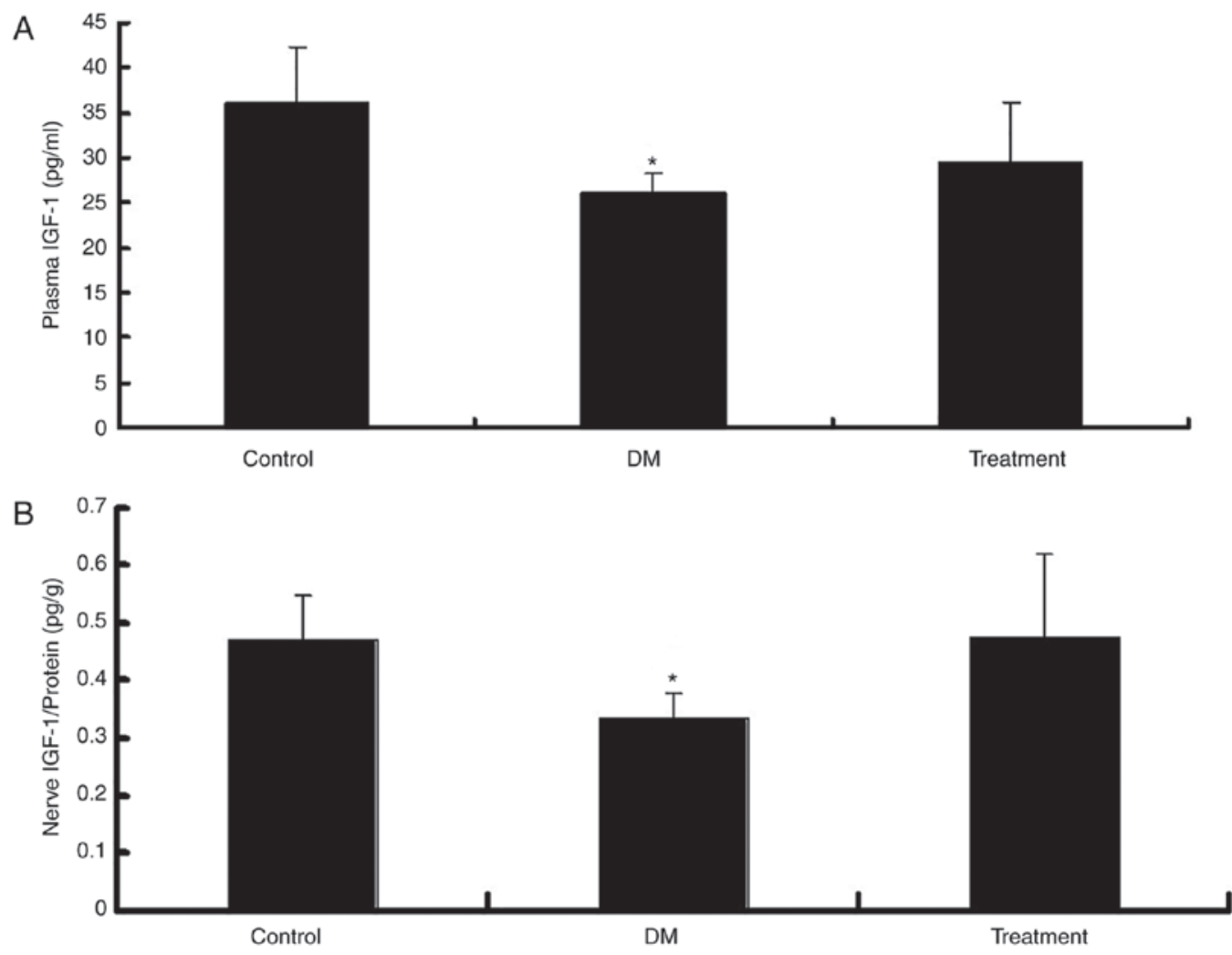

Figure 5. Effect of L-carnitine on IGF-1 levels. IGF-1 content in (A) plasma and (B) sciatic nerves of type 2 diabetic mice with or without L-carnitine treatment. Control, $\mathrm{n}=6$; DM, $\mathrm{n}=5$; Treatment, $\mathrm{n}=5$. $\mathrm{P}<0.05$ vs. the control. DM, diabetes mellitus; IGF-1, insulin-like growth factor-1.

degree of axonal atrophy and myelin sheath swelling, which was different between diabetic nerves and nerves from other groups (Fig. 4). The A/MS of the diabetic group was 0.49 , which was decreased compared with 0.73 in the control group, 0.71 in the pre-treatment group and 0.77 in the treatment group.

IGF-1 content in the plasma and sciatic nerve. To confirm that LC ameliorates peripheral neuropathy in diabetic mice via an increase in IGF-I levels, the IGF-I levels in LC-treated mice were measured. As expected, the IGF-1 levels in the plasma (Fig. 5A) and nerve fibers (Fig. 5B) of diabetic mice were significantly decreased $(\mathrm{P}<0.05)$. However, the exogenous administration of LC in the treatment group normalized the levels of IGF-1 in both the plasma and the sciatic nerve (Fig. 5).

\section{Discussion}

A previous study demonstrated that HFD-fed, STZ-induced, insulin-resistant diabetic mice are good models for patients with T2DM that have risk factors for obesity and distinct metabolic characteristics (35). This model is considered more cost-effective compared with genetic models. In the present study, diabetic mice induced by a combination of STZ and HFD revealed similar characteristics to patients with T2DM patients, including hyperglycemia and obesity. The weight loss caused by LC pre-treatment was expected; however, to the best of our knowledge this has not been reported previously. This could be due to the protective effect of LC and this effect could be used to avoid the harm caused by HFD. Blood glucose levels in the diabetes group were significantly increased, whilst the plasma insulin levels were not increased compared with the control group, which indicated successful induction of T2DM in the mice.

LC is a conditionally essential nutrient that serves a critical role in energy production and fatty acid metabolism (6). Li et al (36) reported that LC could improve clinical symptoms and neurophysiological parameters in patients with DPN. Preclinical trials have revealed the preventive and therapeutic effects of LC on peripheral nerve function and structural abnormalities as well as on endometrial blood flow $(37,38)$. However, little is known about the effect of LC on diabetes mellitus in humans. In the present study, LC levels in the plasma and pancreas were elevated following LC supplementation by intragastric administration.

A previous study indicated that there was no statistical difference in body weight between the diabetes and control group, but food intake of the diabetes group was significantly increased compared with the control group (39). In the present study, the body weight of the pre-treatment group mice was lower compared with the three other experimental groups, which may have prevented the appearance of diabetes. However, the food intake of the pre-treatment and treatment group was lower compared with the diabetes group, which suggested the effect of LC on ameliorating diabetes mellitus. In addition, blood glucose levels of mice treated with LC were lower compared with the diabetic group, which demonstrated the protective effect of LC on hyperglycemia in diabetes mellitus. The results demonstrated that pre-treatment with LC inhibited the development of diabetes. 
DPN occurs with hyperalgesia (40). There were several reports on the changes of nociceptive threshold in experimental diabetic animal models, whereby newly diagnosed diabetes revealed thermal and mechanical hyperalgesia, and long term-treated diabetes demonstrated hypoalgesia (41-43). The alterations to the nociceptive threshold were examined 3 weeks following T2DM induction and hyperalgesia was recorded. The progression of thermal hyperalgesia was attenuated by treatment with LC at both the early and advanced stage of T2DM, which indicated a role for LC in alleviating peripheral neuropathy.

Previous studies indicated that hyperalgesia in diabetic mice is simultaneously followed by a series of neuropathological presentations, including axonal degeneration and segmental demyelination $(44,45)$. Therefore, morphological damage of the sciatic nerve was examined, including axonal atrophy, axonal loss, Schwann cell swelling, demyelination and mitochondrial swelling in neurons. The TEM images revealed stabilized swollen myelin sheaths, regenerated atrophic axons and normalized mitochondria of Schwann cell in LC treated groups, suggesting that LC improved DPN in the present study.

Under experimental conditions, it has been demonstrated that DPN is provoked by multiple interactive pathogenic mechanisms, including oxidative stress, protein kinase $\mathrm{C}$ and microvascular disease (3). Numerous attempts have been made to address the underlying mechanisms therapeutically, but the quantifiable benefits remain limited. Previous studies considered carnitine as an active antioxidant, as carnitine ameliorated DPN by improving cellular energy metabolism by promoting long chain fatty acid $\beta$-oxidation, stimulating glucose disposal and improving insulin resistance further by restoring $\mathrm{Na}^{+} / \mathrm{K}^{+}$-adenosine triphosphatase activity (26). One of these studies also revealed that supplementation with carnitine leads to an increase in IGF-1 levels and activation of the IGF-1/phosphatidylinositol-4,5-bisphosphate 3-kinase $(\mathrm{PI} 3 \mathrm{~K}) /$ protein kinase $\mathrm{B}(\mathrm{Akt})$ signaling pathway in the skeletal muscle of rats (26). Whilst insulin promotes the absorption of glucose from the blood into liver and skeletal muscle cells (46), IGF-1 can directly suppress renal gluconeogenesis in mice, reduce hepatic glucose production and stimulate peripheral glucose uptake (47). In the present study, the levels of IGF-1 in the plasma and sciatic nerves were decreased in type 2 diabetic mice, which was consistent with a previous study (26). The results also demonstrated that LC increased the levels of plasma insulin and IGF-1, and prevented the onset of diabetes. Therefore, the preventive and therapeutic effects of LC on DPN may be mediated through the endogenous IGF-1 system.

The beneficial effects of insulin, C-peptide and IGF-1 on neuropathy have been described, particularly for the treatment of diabetic polyneuropathy (48-50). Insulin is regarded as a nerve promotion factor that upregulates and stabilizes neuron filaments as well as tubulin in a dose-dependent manner. In STZ-induced rats, local unilateral administration of insulin to the sciatic nerve resulted in an increased number of small myelinated fibers and prevented slow nerve conduction in the treated nerve (26). Similarly, IGF-1, which is homologous to insulin and has partial common receptor affinity, can activate post-receptor signaling in neurons to ameliorate diabetic neuropathy (50). Binding of insulin/IGF-I to insulin receptor or IGF-I receptor activates autophosphorylation of the receptor and causes phosphorylation of several intracellular substrate proteins. This in turn leads to activation of the PI3 K/Akt and mitogen-activated protein kinase pathway, which alter neuronal apoptosis-inducing factors (26). Insulin and IGF-1 share certain common effects in diabetes, including increasing glucose uptake, promoting protein synthesis and regulating cell proliferation and differentiation. As a neural growth factor, IGF-1 promotes the regeneration of sensory nerves (51), motor nerves (52) and Schwann cells (53). In addition, IGF-1 can prevent apoptosis of dorsal root ganglion neurons in vitro under high glucose conditions. Therefore, it is reasonable to suggest that IGF-1 mediates the therapeutic effects of LC on DPN.

In conclusion, LC ameliorated peripheral neuropathy in diabetic mice, which may be due to an increase in IGF-I levels. The results indicated that $\mathrm{LC}$ was an effective choice for the relief of symptoms associated with progressive DPN.

\section{Acknowledgements}

Not applicable.

\section{Funding}

The present study was supported by the National Natural Science Foundation of China (grant nos. 31371168 and 31872791).

\section{Availability of data and materials}

The analyzed data sets generated during the study are available from the corresponding author on reasonable request.

\section{Authors' contributions}

RW, LW, JD and RM designed the experiments. RW and LW performed the experiments. CZ, YL, LS and YZ analyzed the data. RW, LW and YZ wrote the manuscript. RM and JD revised the manuscript. All authors reviewed, read and approved the manuscript.

\section{Ethics approval and consent to participate}

The present study was approved by the Ethics Committee of Medical Department of Qingdao University (Qingdao, China).

\section{Patient consent for publication}

Not applicable.

\section{Competing interests}

The authors declare that they have no competing interests.

\section{References}

1. Wooten K: Clinical features and electrodiagnosis of diabetic peripheral neuropathy in the dysvascular patient. Phys Med Rehabil Clin N Am 20: 657-676, 2009.

2. Tesfaye S and Selvarajah D: Advances in the epidemiology, pathogenesis and management of diabetic peripheral neuropathy. Diabetes Metab Res Rev 28 (Suppl 1): S8-S14, 2012. 
3. Sima AA: Diabetic neuropathy: Pathogenetic background, current and future therapies. Expert Rev Neurother 1: 225-238, 2001.

4. Sima AA, Bril V, Nathaniel V, McEwen TA, Brown MB, Lattimer SA and Greene DA: Regeneration and repair of myelinated fibers in sural-nerve biopsy specimens from patients with diabetic neuropathy treated with sorbinil. N Engl J Med 319: 548-555, 1988.

5. Ziegler D, Reljanovic M, Mehnert H and Gries FA: Alpha-lipoic acid in the treatment of diabetic polyneuropathy in Germany: Current evidence from clinical trials. Exp Clin Endocrinol Diabetes 107: 421-430, 1999.

6. Flanagan JL, Simmons PA, Vehige J, Willcox MD and Garrett Q: Role of carnitine in disease. Nutr Metab (Lond) 7: 30, 2010.

7. Salmanoglu DS, Gurpinar T, Vural K, Ekerbicer N, Dariverenli E and Var A: Melatonin and L-carnitin improves endothelia disfunction and oxidative stress in Type 2 diabetic rats. Redox Biol 8: 199-204, 2016.

8. Ido Y, McHowat J, Chang KC, Arrigoni-Martelli E, Orfalian Z, Kilo C, Corr PB and Williamson JR: Neural dysfunction and metabolic imbalances in diabetic rats. Prevention by acetyl-L-carnitine. Diabetes 43: 1469-1477, 1994.

9. Bach AC: Carnitine in human nutrition. Z Ernahrungswiss 21 257-265, 1982.

10. Evans JD, Jacobs TF and Evans EW: Role of acetyl-L-carnitine in the treatment of diabetic peripheral neuropathy. Ann Pharmacother 42: 1686-1691, 2008.

11. Sima AA: Acetyl-L-carnitine in diabetic polyneuropathy: Experimental and clinical data. CNS Drugs 21 (Suppl 1): 13-23, 2007.

12. Stevens MJ, Lattimer SA, Feldman EL, Helton ED, Millington DS, Sima AA and Greene DA: Acetyl-L-carnitine deficiency as a cause of altered nerve myo-inositol content, $\mathrm{Na}, \mathrm{K}-\mathrm{ATPase}$ activity and motor conduction velocity in the streptozotocin-diabetic rat. Metabolism 45: 865-872, 1996.

13. Lowitt S, Malone JI, Salem AF, Korthals J and Benford S: Acetyl-L-carnitine corrects the altered peripheral nerve function of experimental diabetes. Metabolism 44: 677-680, 1995.

14. Onofrj M, Fulgente T, Melchionda D, Marchionni A, Tomasello F, Salpietro FM, Alafaci C, De Sanctis E, Pennisi G, Bella R, et al: L-acetylcarnitine as a new therapeutic approach for peripheral neuropathies with pain. Int J Clin Pharmacol Res 15: 9-15, 1995.

15. Quatraro A, Roca P, Donzella C, Acampora R, Marfella R and Giugliano D: Acetyl-L-carnitine for symptomatic diabetic neuropathy. Diabetologia 38: 123, 1995.

16. Scarpini E, Sacilotto G, Baron P, Cusini M and Scarlato G: Effect of acetyl-L-carnitine in the treatment of painful peripheral neuropathies in HIV+ patients. J Peripher Nerv Syst 2: 250-252, 1997.

17. Sima AA, Calvani M, Mehra M and Amato A; Acetyl-L-Carnitine Study Group: Acetyl-L-carnitine improves pain, nerve regeneration, and vibratory perception in patients with chronic diabetic neuropathy: An analysis of two randomized placebo-controlled trials. Diabetes Care 28: 89-94, 2005.

18. Rajpathak SN, He M, Sun Q, Kaplan RC, Muzumdar R, Rohan TE, Gunter MJ, Pollak M, Kim M, Pessin JE, et al: Insulin-like growth factor axis and risk of type 2 diabetes in women. Diabetes 61: 2248-2254, 2012.

19. Pires KM, Buffolo M, Schaaf C, David Symons J, Cox J, Abel ED, Selzman CH and Boudina S: Activation of IGF-1 receptors and Akt signaling by systemic hyperinsulinemia contributes to cardiac hypertrophy but does not regulate cardiac autophagy in obese diabetic mice. J Mol Cell Cardiol 113: 39-50, 2017.

20. Kanazawa I, Notsu M, Miyake H, Tanaka K and Sugimoto T: Assessment using serum insulin-like growth factor-I and bone mineral density is useful for detecting prevalent vertebral fractures in patients with type 2 diabetes mellitus. Osteoporosis Int 29: 2527-2535, 2018.

21. Cao LH, Lu FM, Lu XJ and Zhu LY: Study on the relationship between insulin growth factor 1 and liver fibrosis in patients with chronic hepatitis $\mathrm{C}$ with type 2 diabetes mellitus. J Cell Biochem 119: 9513-9518, 2018.

22. Dai C, Li N, Song G, Yang Y and Ning X: Insulin-like growth factor 1 regulates growth of endometrial carcinoma through PI3k signaling pathway in insulin-resistant type 2 diabetes. Am J Transl Res 8: 3329-3336, 2016.
23. Hjortebjerg R, Laugesen E, Høyem P, Oxvig C, Stausbøl-Grøn B, Knudsen ST, Kim WY, Poulsen PL, Hansen TK, Bjerre M and Frystyk J: The IGF system in patients with type 2 diabetes: Associations with markers of cardiovascular target organ damage. Eur J Endocrinol 176: 521-531, 2017.

24. Katz LE, DeLeón DD, Zhao H and Jawad AF: Free and total insulin-like growth factor (IGF)-I levels decline during fasting. Relationships with insulin and IGF-binding protein-1. J Clin Endocrinol Metab 87: 2978-2983, 2002.

25. Ge P, Cui Y, Liu F, Luan J, Zhou X and Han J: L-carnitine affects osteoblast differentiation in NIH3T3 fibroblasts by the IGF-1/PI3K/Akt signalling pathway. Biosci Trends 9: 42-48, 2015.

26. Keller J, Couturier A, Haferkamp M, Most E and Eder K: Supplementation of carnitine leads to an activation of the IGF-1/PI3 K/Akt signalling pathway and down regulates the E3 ligase MuRF1 in skeletal muscle of rats. Nutr Metab (Lond) 10: $28,2013$.

27. Xia Y, Li Q, Zhong W, Dong J, Wang Z and Wang C: L-carnitine ameliorated fatty liver in high-calorie diet/STZ-induced type 2 diabetic mice by improving mitochondrial function. Diabeto Metab Syndr 3: 31, 2011.

28. Reed MJ, Meszaros K, Entes LJ, Claypool MD, Pinkett JG, Gadbois TM and Reaven GM: A new rat model of type 2 diabetes: the fat-fed, streptozotocin-treated rat. Metabolism 49: 1390-1394, 2000

29. Cao Y, Wang YX, Liu CJ, Wang LX, Han ZW and Wang CB: Comparison of pharmacokinetics of L-carnitine, acetyl-Lcarnitine and propionyl-L-carnitine after single oral administration of L-carnitine in healthy volunteers. Clin Invest Med 32 E13-E19, 2009

30. Tisi A, Federico R, Moreno S, Lucretti S, Moschou PN, Roubelakis-Angelakis KA, Angelini R and Cona A: Perturbation of polyamine catabolism can strongly affect root development and xylem differentiation. Plant Physiol 157: 200-215, 2011.

31. De Palo E, Gatti R, Sicolo N, Padovan D, Vettor R and Federspil G: Plasma and urine free L-carnitine in human diabetes mellitus. Acta Diabetol Lat 18: 91-95, 1981.

32. McGeoch SC, Holtrop G, Fyfe C, Lobley GE, Pearson DW, Abraham P, Megson IL, Macrury SM and Johnstone AM: Food intake and dietary glycaemic index in free-living adults with and without type 2 diabetes mellitus. Nutrients 3: 683-693, 2011.

33. Hur J, Dauch JR, Hinder LM, Hayes JM, Backus C, Pennathur S, Kretzler M, Brosius FC III and Feldman EL: The metabolic syndrome and microvascular complications in a murine model of type 2 diabetes. Diabetes 64: 3294-3304, 2015.

34. Ding Y, Dai X, Zhang Z, Jiang Y, Ma X, Cai X and Li Y: Proanthocyanidins protect against early diabetic peripheral neuropathy by modulating endoplasmic reticulum stress. J Nutr Biochem 25: 765-772, 2014

35. Srinivasan K and Ramarao P: Animal models in type 2 diabetes research: An overview. Indian J Med Res 125: 451-472, 2007

36. Li S, Chen X, Li Q, Du J, Liu Z, Peng Y, Xu M, Li Q, Lei M, Wang C, et al: Effects of acetyl-L-carnitine and methylcobalamin for diabetic peripheral neuropathy: A multicenter, randomized, double-blind, controlled trial. J Diabetes Investig 7: 777-785, 2016.

37. Fagher B, Cederblad G, Eriksson M, Monti M, Moritz U, Nilsson-Ehle P and Thysell H: L-carnitine and haemodialysis: Double blind study on muscle function and metabolism and peripheral nerve function. Scand J Clin Lab Invest 45: 169-178, 1985.

38. Arioz DT, Kanat-Pektas M, Tuncer N, Koken T, Unlu BS, Koken $\mathrm{G}$ and Yilmazer M: L-Carnitine: A new insight into the pathogenesis of endometrial cancer. Arch Gynecol Obstet 291: $1147-1152,2015$

39. Zhang M, Lv XY, Li J, Xu ZG and Chen L: The characterization of high-fat diet and multiple low-dose streptozotocin induced type 2 diabetes rat model. Exp Diabetes Res 2008: 704045, 2008.

40. Jolivalt CG, Frizzi KE, Guernsey L, Marquez A, Ochoa J, Rodriguez $\mathrm{M}$ and Calcutt NA: Peripheral neuropathy in mouse models of diabetes. Curr Protoc Mouse Biol 6: 223-255, 2016

41. Drel VR, Mashtalir N, Ilnytska O, Shin J, Li F, Lyzogubov VV and Obrosova IG: The leptin-deficient (ob/ob) mouse: A new animal model of peripheral neuropathy of type 2 diabetes and obesity. Diabetes 55: 3335-3343, 2006

42. Ohsawa M, Miyata S, Carlsson A and Kamei J: Preventive effect of acetyl-L-carnitine on the thermal hypoalgesia in streptozotocin-induced diabetic mice. Eur J Pharmacol 588: 213-216, 2008. 
43. Calcutt NA, Freshwater JD and Mizisin AP: Prevention of sensory disorders in diabetic Sprague-Dawley rats by aldose reductase inhibition or treatment with ciliary neurotrophic factor. Diabetologia 47: 718-724, 2004.

44. Malik RA: Pathology of human diabetic neuropathy. Handb Clin Neurol 126: 249-259, 2014

45. Dyck PJ and Giannini C: Pathologic alterations in the diabetic neuropathies of humans: A review. J Neuropathol Exp Neurol 55 1181-1193, 1996

46. Dimitriadis G, Mitrou P,Lambadiari V, Maratou E and Raptis SA Insulin effects in muscle and adipose tissue. Diabetes Res Clin Pract 93 (Suppl 1): S52-S59, 2011.

47. Simpson HL, Jackson NC, Shojaee-Moradie F, Jones RH Russell-Jones DL, Sönksen PH, Dunger DB and Umpleby AM: Insulin-like growth factor I has a direct effect on glucose and protein metabolism, but no effect on lipid metabolism in type 1 diabetes. J Clin Endocrinol Metab 89: 425-432, 2004.

48. de la Hoz CL, Cheng C, Fernyhough P and Zochodne DW: A model of chronic diabetic polyneuropathy: Benefits from intranasal insulin are modified by sex and RAGE deletion. Am J Physiol Endocrinol Metab 312: E407-E419, 2017.

49. Kamiya H, Zhang W and Sima AA: The beneficial effects of C-Peptide on diabetic polyneuropathy. Rev Diabet Stud 6: $187-202,2009$
50. Gao T, Bogdanova N, Ghauri S, Zhang G, Lin J and Sheikh K: Systemic IGF-1 gene delivery by rAAV9 improves spontaneous autoimmune peripheral polyneuropathy (SAPP). Sci Rep 8: $5408,2018$.

51. Fernyhough P, Willars GB, Lindsay RM and Tomlinson DR: Insulin and insulin-like growth factor I enhance regeneration in cultured adult rat sensory neurones. Brain Res 607: 117-124, 1993.

52. Near SL, Whalen LR, Miller JA and Ishii DN: Insulin-like growth factor II stimulates motor nerve regeneration. Proc Natl Acad Sci USA 89: 11716-11720, 1992.

53. Chang YM, Kuo WH, Lai TY, Shih YT, Tsai FJ, Tsai CH, Shu WT, Chen YY, Chen YS, Kuo WW and Huang CY: RSC96 schwann cell proliferation and survival induced by dilong through PI3K/Akt signaling mediated by IGF-I. Evid Based Complement Alternat Med 2011: 216148, 2011. 